\title{
Extended Collective Licensing for the Use of Out-of- Commerce Works in Europe: A Matter of Legitimacy Vis-à-Vis Rights Holders
}

\author{
Lucie Guibault $\cdot$ Simone Schroff
}

Published online: 28 August 2018

(C) The Author(s) 2018

\begin{abstract}
Extended Collective Licensing (ECL) schemes have been put forward in Europe as one of the solutions for the licensing of out-of-commerce works by cultural heritage institutions. ECL schemes extend the application of freely negotiated copyright licensing agreements between a user and a collective management organisation (CMO) to the works of non-members of the organisation. Not every CMO is suitable to license works under ECL provisions, however. In particular, the legitimacy of any agreement crucially relies on the "representativeness" of the CMO. This article focuses on the notion of representativeness of CMOs. On the basis of current European and national legislation, we argue that the representative character of a CMO encompasses three essential elements to be considered from the perspective of the rights owners: (1) the CMO must have a broad membership among the potential rights owners in the market it serves; (2) it must have a proper mandate from the rights owners in terms of category of works and rights covered; and (3) it must take appropriate measures to reach and inform (non-)members about the exercise of rights. ECL schemes can only be sufficiently legitimate to presume tacit approval by non-members if this assessment of the three criteria is carried out carefully.
\end{abstract}

Lucie Guibault is an honorary fellow of the Institute for Information Law at the University of Amsterdam, The Netherlands. Simone Schroff is a visiting Scholar at Waseda University, Japan.

L. Guibault $(\bowtie)$

PhD; Associate Professor of Law; Associate Director, Law \& Technology Institute, Dalhousie University, Halifax, Canada

e-mail: Lucie.Guibault@dal.ca

S. Schroff

Post-doctoral Researcher at the Institute for Information Law, University of Amsterdam, Amsterdam, The Netherlands

e-mail: S.Schroff@uva.nl 
Keywords Copyright · Extended collective licensing · Collective management organisations · Representativeness · Mandate

\section{Introduction}

In recent years, numerous projects across the EU have focused on the large-scale digitisation of cultural heritage materials. These projects are usually carried out by cultural heritage institutions (CHIs). In line with their mandate, their aim is to preserve and make available cultural assets, implying that the focus is on older materials that would not otherwise be accessible. Copyright law is a crucial component of these digitisation efforts. Much of the 20th century material held by CHIs in their collections is still in copyright due to the long terms of protection. ${ }^{1}$ In particular for works that are no longer available through the usual commercial channels, digitisation has benefits for everyone: the right holders receive income not otherwise available; the CHIs are able to continue to fulfil their public interest mission; while the public gains access to previously unavailable works. ${ }^{2}$ As European CHIs cannot rely on copyright exemptions to digitise works and make them accessible online, ${ }^{3}$ they instead must seek a license from the right holder. In principle, licensing a work requires three distinct steps: (a) identifying and locating the owner(s) of rights, (b) negotiating a price, and (c) monitoring and enforcement. Each one of these steps imposes a cost on either the licensor or the licensee. ${ }^{4}$ As a result, this process can be very onerous for both parties: the user must invest resources in locating the rights owner and negotiating the license; and the right holder must bear part of the negotiation cost, in addition to the cost imposed by the monitoring and enforcement of the license. If the costs of rights clearance are greater than the expected benefits of digitisation, works will not be digitised irrespective of the technological possibilities. ${ }^{5}$

The problem of having to provide licenses to a large number of users is not new and has traditionally been solved by Collective Management Organisations (CMOs). In essence, they collect the royalties for high-volume but low-value non-exclusive uses, such as performance of a work in public or its online exploitation. ${ }^{6}$ CMOs are in practice the major licensing intermediary between the right holder and the user. In general terms, CMOs manage the rights of their members and permit their use by licensees based on a set of defined tariffs in return for payment. The role of CMOs in the licensing process can be best understood as a way of outsourcing the licensing process to a third party. CMOs work on the basis of assignment of rights, whereby authors assign their rights to the CMO upon

\footnotetext{
1 Gomez and Keller (2015).

2 Bensamoun (2014), p. 215.

3 The license has to cover the reproduction and making available right under Arts. 2 and 3 InfoSoc Directive. At the same time, none of the exceptions covers mass digitisations projects.

4 Kretschmer (2005), p. 6.

5 Axhamn and Guibault (2011), p. 510.

${ }^{6}$ Haunss (2013), p.1.
} 
becoming a member. ${ }^{7}$ On this basis, the CMO is entitled to grant licences to the users, as well as to monitor and enforce the users' compliance with these licences, relieving the right holder of this duty. In other words, CMOs ensure that users pay according to the rules.

CMOs rarely cover all possible rights owners within their jurisdiction, however. ${ }^{8}$ To make mass digitisation economically viable in practice, a solution must be found in order to cover as many rights owners as possible, including non-members. In principle, this can be achieved in one of three ways: (1) mandatory statutory licensensing, (2) voluntary opt-in agreements, and (3) Extended Collective Licensing (ECL) schemes. ${ }^{9}$ ECL is less intrusive than the first option while at the same time still providing large scale coverage that opt-ins cannot achieve. ${ }^{10}$ ECL is a form of exercise of rights whereby the law extends the application of freely negotiated copyright licensing agreements between a user, like a CHI, and a CMO to the rights of non-members of the organisation. ${ }^{11}$ Compared to standard collective rights management, the "extension" of agreements to non-members of a CMO significantly facilitates the licensing process, knowing that even if not all rights owners are identified, license agreements can still be concluded and remuneration paid, allowing the use to take place under specific conditions. At the same time, the free negotiations between the CMO representing the right holders and the user associations are likely to lead to higher remuneration levels than a compulsory license system would. ${ }^{12}$

Not every CMO is suitable to license works under ECL provisions, however. In particular, the legitimacy of any agreement crucially relies on the "representativeness" of the CMO. The representative character of the CMO is a question of legitimacy towards the (non-)members of the CMO, as well as of legal certainty towards the users: (1) a "representative" CMO will exercise the rights of a large enough number of rights holders to legitimise the application of the agreement to all rights owners, including non-members; while (2) a "representative" CMO will be able to grant a licence with broad coverage of the repertoire which increases the legal certainty for the users. A CMO that does not represent a sufficiently high number of rights owners cannot claim to negotiate a legitimate agreement with users on behalf of all rights holders, nor can it give any assurance to the user that the repertoire covered is sufficient to reduce the risk of having a (large number of) nonmembers opt-out from it. ${ }^{13}$

The principle of CMO representativeness comes back as a mantra every time the suggestion is made to create an ECL regime to solve the copyright problems associated with the use of out-of-commerce works by CHIs, including in the

\footnotetext{
7 The transfer can be exclusive or non-exclusive, depending on the legal context. It is usually exclusive though.

${ }^{8}$ For a detailed discussion, see below Sects. 2.1 and 2.2.

9 Busse (2018), p. 147.

${ }^{10}$ Busse (2018), p. 147.

${ }^{11}$ For a history of ECL schemes within Europe, please see Zhang (2016), pp. 658-661.

12 Axhamn and Guibault (2011), p. 513.

13 Guibault (2015), p. 173.
} 
Proposal for a Directive on Copyright in the Digital Single Market $^{14}$ (DSM Proposal). Without a sufficient degree of representativeness, ECLs indeed bear the risk of becoming illegitimate. But what does "representativeness" of a CMO entail in practice? When can one be satisfied that a CMO is sufficiently representative so as to guarantee its legitimacy vis-à-vis all rights owners? Until the publication of the DSM Proposal in September 2016, the European legislature had devoted only scant attention to the issue of representativeness of CMOs. Even Directive 2014/26/EC on the Collective Management of Copyrights ${ }^{15}$ does not explicitly address the issue. And while some aspects of the issue have been examined by the Court of Justice of the European Union (CJEU) in the Soulier and Doke case, ${ }^{16}$ the question has yet to be examined in depth.

This article focuses on the notion of representativeness of CMOs, generally and as it relates to the implementation of an ECL regime in particular. The provisions governing the use of out-of-commerce works by CHIs in the current DSM Proposal are many years in the making. They find their origin in the Memorandum of Understanding on Key Principles on the Digitisation and Making Available of Outof-Commerce Works (MoU), ${ }^{17}$ signed in 2011, between the relevant stakeholders in the print sector, under the auspices of the European Commission. In addition, the relationship between CMOs and their members has been subject to EU harmonisation in the Directive of the European Parliament and of the Council on collective management of copyright and related rights and multi-territorial licensing of rights in musical works for online uses in the internal market. ${ }^{18} \mathrm{We}$ argue that on the basis of the MoU, the CMO Directive and the DSM Proposal, the representative character of a CMO encompasses three essential elements to be considered from the perspective of rights owners: (1) the CMO must have a broad membership among the potential rights owners in the market it serves; (2) it must have a proper mandate from the rights owners in terms of category of works and rights covered; and (3) it must take appropriate measures to reach and inform (non-)members about the exercise of rights.

The first part of this paper gives a brief description of the European legal framework, including the MoU, the Directive of 2014 on the Collective Management of Rights and the relevant provisions of the DSM Proposal. The second part takes a look at the three constituting elements of the concept of

\footnotetext{
14 Proposal for a Directive of the European Parliament and of the Council on Copyright in the Digital Single Market - COM(2016)593 (DSM Directive), 14 September 2016, [hereinafter DSM Proposal], available at: https://ec.europa.eu/digital-single-market/en/news/proposal-directive-european-parliamentand-council-copyright-digital-single-market.

15 Directive 2014/26/EU of the European Parliament and of the Council of 26 February 2014 on collective management of copyright and related rights and multi-territorial licensing of rights in musical works for online use in the internal market [hereinafter CMO Directive], OJ L 84, 20.3.2014, pp. 72-98.

16 Case C-301/15, Decision of the Court of Justice of the European Union, 16 November 2016 (Soulier and Doke).

17 Memorandum of Understanding - Key Principles on the Digitisation and Making Available of Out-ofCommerce Works [hereinafter MoU], Signed on 20 September 2011, principle 1, para. 1, available at: http://ec.europa.eu/internal_market/copyright/docs/copyright-infso/20110920-mou_en.pdf.

18 CMO Directive.
} 
representativeness through the lens of EU law, in particular the CJEU in Soulier and Doke. It is our reading of the CJEU's decision in the Soulier and Doke case that the Court dealt exclusively with the third component of representativeness, overlooking the first two elements. Were this narrow interpretation of the notion of representativeness to be followed in the future, it would risk seriously undermining the required representative character of CMOs in general and those engaged in ECL schemes in particular.

\section{Out-of-Commerce Works: The Emergence of the ECL Solution}

The question of ECL legitimacy is not new and has been discussed at EU level before. Most notably, there are a number of soft and hard law instruments which influence how representativeness should be interpreted. In this section, these instruments will be analysed in terms of their content and how they relate to the interpretation of when a $\mathrm{CMO}$ is representative.

\subsection{The Memorandum of Understanding on the Use of Out-of-Commerce Works}

In the context of the stakeholder dialogue facilitated by the European Commission, the right holders in books and CHIs agreed on a basic outline for mass digitisation. ${ }^{19}$ This first step towards the creation of a solution for the dissemination of out-ofcommerce (hereinafter OOC) books is the Memorandum of Understanding - Key Principles on the Digitisation and Making Available of Out-of-Commerce Works, a non-binding instrument of soft law. ${ }^{20}$ The MoU was meant as an enabler of digitisation and easy online dissemination of OOC works to foster large-scale digitisation initiatives. ${ }^{21}$ It was limited to books and articles that are "out-ofcommerce", meaning books and "learned" articles that are copyright-protected but are no longer commercially available. Following the Nordic practice, the essence of the MoU was to suggest an ECL model. ${ }^{22}$

The Key Principles set out in the MoU referred to all three elements of the requirement of representativeness of CMOs involved in the digitisation and dissemination of OOC books. With respect to the breadth of the membership, Principle No. 2.1 states:

Licences for works that are out of commerce will only be granted by collective management organisations in which a substantial number of authors and publishers affected by the Agreement are members, and appropriately represented in the key decision making bodies. [emphasis added]

\footnotetext{
19 Janssens and Tryggvadottir (2016), p. 203.

${ }^{20}$ MoU, principle 1, para. 1. See also Janssens and Tryggvadottir (2016), p. 207.

21 Beunen and Guibault (2011), pp. 221-222.

22 For an explanation of the Nordic model, see Zhang (2016); or Hugenholtz et al. (2014).
} 
This language is modeled after the Nordic legislation regulating ECL regimes. Accordingly, only those CMOs that already manage the type of work in question (here books) by representing authors and publishers can benefit from the MoU. At the same time, there is widespread recognition that the determination of what constitutes a "substantial number" of rights owners has the potential of being highly subjective. No further guidance is given on this crucial point.

However, the extended effect is subject to further efforts by the CMO. Principle No. 2.4 specifies:

For the purpose of such an Agreement, where a rightholder whose work was first published in a particular Member State has not transferred the management of his rights to a collective management organisation, the collective management organisation which manages rights of the same category in that Member State of first publication shall be presumed to manage the rights in respect of such work. In order to benefit from this presumption the collective management organisation shall make its best efforts to alert rightholders in question in accordance with information procedure methods agreed upon with organisations representing rightholders in the country where the collective management organisation is based. The rightholder organisations will commit to assist the collective management organisation in the work to alert authors and publishers. ${ }^{23}$ [emphasis added]

This provides information on the other two representativeness requirements. First, the CMO in question needs to have a mandate from its members to manage the relevant exclusive right (e.g. making available online). Secondly, only those CMOs already working within the jurisdiction of first publication, the presumed home state or permanent residence of the rights owner, are entitled to represent non-users. Therefore, the MoU establishes that a $\mathrm{CMO}$ is the representative for a particular member state and a certain type of work and right. This implies that representativeness is a question of degree which varies when the parameters change. It cannot therefore be presumed that the same CMO is always the most suitable one. Instead, any assessment has to be context dependant. There is no guidance, however, on what this assessment would actually entail in practice.

Overall, the MoU covers all three points of representativeness as we understand them: broad membership, a mandate to manage the right in question (here making available), and information campaigns for non-members to ensure that they can opt out if they wish. However, none of these points is given any substance; they are only mentioned but not more closely defined. In addition, the $\mathrm{MoU}$ also relies on the principle of national jurisdiction, reflecting the assumption that coverage of a $\mathrm{CMO}$ in its own territory is larger than the coverage of any other organisation.

${ }^{23}$ MoU, Principle No. 2(4). 


\subsection{The Collective Rights Management Directive}

The 2014 CMO Directive ${ }^{24}$ does not discuss ECL schemes as such but adds to the notion of representativeness because it shapes the relationship between the rights owners and the CMO. In difference to the MoU, the CMO Directive is not concerned with cultural heritage as such but ensures that all CMOs across the European Union are bound by common standards of governance. It therefore addresses a core issue in the (Digital) Single Market: CMOs are essential to the use of copyright works because they lower the transaction costs involved by providing licenses without the need to contact individual right holders while at the same time ensuring that royalties reach the relevant right holders. ${ }^{25}$ In practice, the economic benefit of CMOs is based on a legal or de facto monopoly, ${ }^{26}$ giving rise to competition issues. ${ }^{27}$ As a result, the traditional EU-level approach is strongly influenced by a competition paradigm which is also reflected in the CMO Directive. $^{28}$

In this context, the purpose of the Directive of the European Parliament and of the Council on collective management of copyright and related rights and multiterritorial licensing of rights in musical works for online uses in the internal market is two-fold: first, to establish rules on transparency and good governance for the collective management of copyright and related rights; and second, to create a legal framework which promotes the development, in the field of music-making, of multiterritory and multi-directory licensing by collective management organisations. In the context of ECLs, it is the provisions on the relationship between the individual right holders and the CMO which are most important. ${ }^{29}$

The CMO Directive clearly defines the rights of right holders vis-à-vis a CMO. Article 4 of the Directive insists that Member States ensure that

collective management organisations act in the best interests of the rightholders whose rights they manage and that they do not impose on them any obligations which are not objectively necessary for the protection of their rights and interests or for the effective management of their rights.

This means any CMO is to be the least imposing it can be while maintaining an efficient rights management regime. In other words, they are to represent the right holder and act in his interests, not overriding his preferences unless it is objectively necessary to do so for the benefit of all right holders collectively. One key area in this respect is the mandate a right holder gives a CMO.

\footnotetext{
${ }^{24}$ Directive 2014/26/EU of the European Parliament and of the Council of 26 February 2014 on collective management of copyright and related rights and multi-territorial licensing of rights in musical works for online use in the internal market OJ L 84, 20.3.2014, p. 72-98 (CMO Directive).

25 Haunss (2013), p. 1.

26 Drexl et al. (2013), p. 325.

27 For a detailed analysis, please see Kretschmer (2005), p. 7.

28 Schroff and Street (2017) for a historical overview and the influence of the competition paradigm.

29 Guibault (2014), p. 700.
} 
What a CMO can consider as its mandate is shaped by Art. 5. In principle, right holders are free to choose any CMO within the EU, including dividing their rights, categories of works and territory. ${ }^{30}$ The CMO in this case has to facilitate the choice as it has the duty to actively inform its (prospective) member that they are free to choose the $\mathrm{CMO}$ and are not bound by jurisdiction. ${ }^{31}$ It is therefore possible that the same author assigns the rights in some works to CMO "A" but others to CMO "B". In line with this, CMOs have to be clear about what kinds of rights they actually manage and, "in cases where a rightholder authorises a collective management organisation to manage his rights, he shall give consent specifically for each right or category of rights or type of works and other subject-matter which he authorises the collective management organisation to manage. Any such consent shall be evidenced in documentary form". 32 This is crucial for CMOs in particular because all management claims by a CMO are based on these contracts and do not extend beyond them. Furthermore, following from the freedom of choice, right assignments are not static. For example, a right holder can withdraw from a $\mathrm{CMO},{ }^{33}$ irrespective of whether he assigns the rights to another one. ${ }^{34}$ To reduce the negative impact of these decisions on the right holder, he keeps the proceeds of withdrawn rights. ${ }^{35}$ Most notably in the context of digitisation projects, the CMO cannot prevent the right holder from permitting non-commercial uses directly, even if he entrusted a CMO with the management of the relevant right. ${ }^{36}$ Most large-scale digitisation projects undertaken by CHIs would fall into this category, meaning that every right holder can in principle give CHIs direct permission irrespective of the managing CMO's position.

The CMO Directive's second relevant aspect for ECL schemes lies in its rules on the treatment of non-members. While these are significantly less detailed than the provisions on members, they nonetheless provide some guidance. First, CMOs are required to actively identify and trace right holders when revenues are collected for them. ${ }^{37}$ The aim is to ensure that all right holders receive their revenues within nine months after the year the revenues are initially collected. ${ }^{38}$ Most notably, if they fail to distribute the funds on time, the revenues are to be kept in a separate account for at least three years, ${ }^{39}$ enabling future distribution. Right holders need to be actively

\footnotetext{
${ }^{30}$ CMO Directive, Art. 5(2). According to the Directive, the CMO has a duty to manage rights unless there are objectively justifiable reasons not to do so. One such reason could be high administrative costs as established in the Daft Punk case, EC, 12 August 2002, Case COMP/C2/37.219, Banghalter and Homem Christo v. SACEM.

31 CMO Directive, Art. 5(8).

32 CMO Directive, Art. 5(7).

33 CMO Directive, Art. 5(4).

34 CMO Directive, Art. 5(6).

35 CMO Directive, Art. 5(5).

36 CMO Directive, Art. 5(3). Metzger and Heinemann (2015).

37 CMO Directive, Art. 13(3).

38 CMO Directive, Art. 13(1).

39 CMO Directive, Art. 13(2) and (4). It should be noted here that the use of non-claimed revenues for which the right holder could not be identified has to be decided by the General Assembly, in line with the specific CMO's statute of limitations. (Art. 13(5)).
} 
traced using all available options, first via other CMOs, public records and then via the public. ${ }^{40}$ This explicitly also includes right holders who have withdrawn from a CMO but are still owed revenues. ${ }^{41}$ In other words, CMOs are required under the CMO Directive to treat non-members on the same basis as their own members in respect to the collected revenues. They must actively trace members, and safeguards are built in to ensure that uncollected revenues are not spent or redistributed for at least three years, giving the non-member time to collect.

The protection of non-members in turn crucially depends on the third key area in the CMO Directive when studied from the point of view of ECL schemes transparency. To ensure CMO actions are transparent to (non-)members, Chapter 5 of the CMO Directive sets minimum standards. A right holder who is not a member of the CMO is treated under the CMO Directive as a member of the public, making Art. 21 applicable. It lists the kinds of information any CMO has to make available to the general public, referring mainly to the general organisational statutes (e.g. articles of association and membership terms), ${ }^{42}$ aspects of revenue collection and distribution (e.g. the tariff structures, distribution of revenues and deductions), ${ }^{43}$ as well as details on the dispute resolution procedures. ${ }^{44}$ The second source of information is in the transparency report, which each CMO is required to publish within eight months after the financial year has ended. ${ }^{45}$ Under Part 2 of the Annex, the transparency report must provide the overall income and costs associated with the rights management. ${ }^{46}$ While the revenues and costs have to be divided by category of work and right, it is essentially an aggregate. This means that it would not allow an individual right holder to assess how much he is owed in the event of a dispute. Overall, this information is designed to allow a right holder who is not a member of the CMO in question to identify what the CMO licenses, with whom it cooperates, how the revenue is calculated and where to turn to if there are issues. It should be noted though that the actual amounts collected are not included in the list. $^{47}$

In summary, the primary importance of the CMO Directive for ECL schemes lies in its provision on the mandate. A CMO mandate is based on the contracts between the CMO and its members. They only cover what is explicitly listed and do not extend beyond. This means for OOC schemes that only those CMOs which list the digitising and making available rights explicitly in the statutes and membership contracts qualify. There is no presumed extension of mandate at any time. More broadly speaking, the representativeness of the CMO is crucially dependant on the contracts it has with its members whereby the coverage of these contracts has to be interpreted narrowly. As with the MoU, this implies that there cannot be a

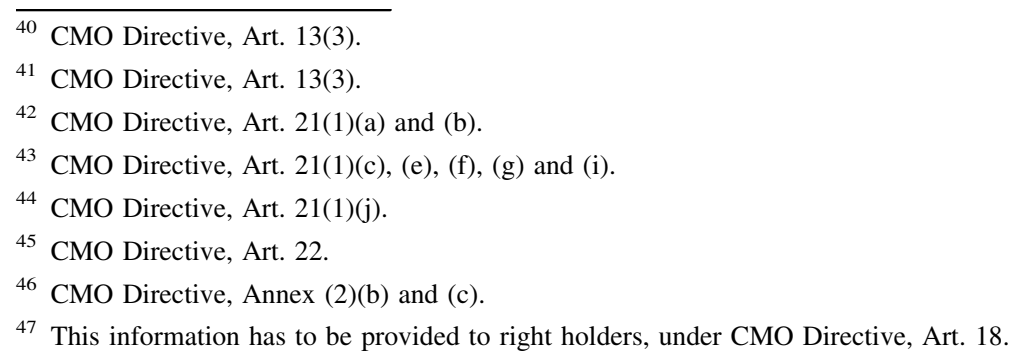


presumption of CMO representativeness. The second key significance of the CMO Directive is in its rules on non-members. If revenues are collected for works which are not covered by the CMO's own catalogue, the CMO must actively search for the right holder. It also has to keep the revenues collected in a separate account for at least three years, ensuring that a right holder can still be paid even if some time has passed. In addition, the non-member receives access to information under the transparency rules. These should enable him to identify if a CMO is likely to have collected revenue due to him, even if he cannot determine how much it is. Furthermore, by ensuring that CMOs make their dispute resolution procedures public and actively provide information on them, they facilitate the process of right holders using them.

\subsection{The Proposed Directive on Copyright in the Digital Single Market}

In practice, neither the MoU nor the CMO Directive ${ }^{48}$ has solved the issue of the collective licensing of OOC works by CHIs sufficiently. The DSM Proposal would introduce for the first time a solution for the mass-digitisation rights clearance issues faced by CHIs. In the compromise text of the Proposal, Art. 7(1) provides that:

Member States shall provide that a collective management organisation, in accordance with its mandates, may conclude a non-exclusive licence for noncommercial purposes with a cultural heritage institution for the reproduction, distribution, communication to the public or making available to the public of out-of-commerce works or other subject-matter permanently in the collection of the institution, irrespective of whether all rightholders covered by the licence have mandated the collective management organisation ... 49

Most notably, Art. 7 defines the context in which a CMO may grant a licence to a CHI. Article 7 applies to the distribution and not only digitisation, communication to the public and making available online, as long as the licenses are not exclusive. In other words, the $\mathrm{CHI}$ will at no point be able to exclude any third party from using the work online, as long as the grant of such a licence falls within its mandate. The aim of Art. 7 of the DSM Proposal in this sense is clearly meant to allow the use of material held by CHIs in both a tangible and intangible form for their noncommercial activities. The list of economic activities covered marks the maximum scope of a possible voluntary agreement between a CMO and a $\mathrm{CHI}$, not the entitlement of the licensee. In other words, agreements as narrow as only allowing for communication to the public or making available online also benefit from the ECL effect as long as the voluntary agreements are non-exclusive and for noncommercial purposes. In other words, the scope of the license is entirely determined by the voluntary agreement, not by the provision providing for the extended effect. It is, as a result, also possible that different CMOs are most representative for the

\footnotetext{
${ }^{48}$ Or indeed the Orphan Works Directive which is deemed too expensive due to the diligent search requirement. Janssens and Tryggvadottir (2014), p. 36.

49 2016/0280 (COD), Brussels, 25 May 2018.
} 
different activities and indeed more than one ECL may be required to cover all of the activities listed in the DSM Proposal.

In terms of representativeness, the Directive Proposal states under Art. 7(1)(a): "the collective management organisation is, on the basis of mandates from rightholders, sufficiently representative of rightholders in the type of works or other subject-matter and of the rights which are the subject of the licence."

Most notably, the DSM Proposal combines the notions laid out earlier. On one hand, it refers to the type of works and other subject-matter as already known from the MoU, while the notion of mandate referred to in the DSM is essentially a codification of the CMO Directive's provisions; the basis for any assessment has to be the contracts a CMO has with its members. Therefore, only explicitly listed items may be taken into consideration - there is no possibility to extend the interpretation of the scope under the law. In addition to the general rule, the DSM Proposal further specifies that representativeness is to be assessed in relation to the country where the $\mathrm{CHI}$ is established ${ }^{50}$ : "Member States shall ensure that the licences referred to in paragraph 1 are sought from a collective management organisation that is representative for the Member State where the cultural heritage institution is established."

The underlying assumption is that the CMO in the member state where a work was first published is likely to be most representative. ${ }^{51}$ Article 7(5) of the compromise text of the DSM Proposal no longer defines the circumstances of when a work is to be considered first published or broadcast in a member state. Instead, the proposed provision excludes "sets of out-of-commerce works", if following the reasonable effort to determine commercial availability, there is evidence to suggest that the work or other subject-matter originates from a third country. Point (a) defines works or other subject-matter (with the exception of cinematographic and audio-visual works) as originating from a third country where they were first published or broadcast. Regarding audio-visual or cinematographic works, in point (b), the headquarters or habitual residence provide the location identification criteria. Point (c) is the residual provision according to which the OOC work or other subject-matter of a third country national is excluded from the application of the regime when a member state or a third country cannot be determined, after a reasonable effort, according to points (a) and (b). ${ }^{52}$ This last point addresses the critique against the initial text of the DSM Proposal according to which there was no built-in presumption that works that could not be clearly identified as EU works were automatically deemed non-EU works. Finally Art. 7(5) in fine specifies that the regime does not apply to sets of OOC works from a third country unless the CMO is sufficiently representative of rights holders in that third country in the meaning of

\footnotetext{
50 DSM Proposal, Art. 7(4).

51 Guibault (2015). This has the side effect of reducing the foreign authors issue. If an ECL scheme is based on the jurisdiction of the user, then a large part of the affected works are potentially from another country, especially if the language is common. As a result, the percentage of foreign authors increases and with it the probable size of the non-member portion. Strowel (2011), p. 669.

52 The Orphan Works Directive includes a similar rule. Directive 2012/28/EU of the European Parliament and of the Council of 25 October 2012 on certain permitted uses of orphan works [hereinafter Orphan Works Directive], OJ L 299, 27.10.2012, pp. 5-12 especially Arts. 1 and 3.
} 
Art. 7(1)(a). The global representativeness of a CMO, i.e. whether it is sufficiently representative of rights holders in the member state where the $\mathrm{CHI}$ is located and in the third country XXXX, will be a matter of evidence to be assessed on a case-bycase basis.

The last provision de facto defining the notion of mandate in the DSM Proposal relates to opt-outs in Art. 7(1)(c): "all rightholders may at any time exclude the possibility for collective management organisations to license their works or other subject-matter in accordance with this Article, either in general or in specific cases, or exclude the application of any licence granted in accordance with this Article to their works or other subject-matter."

This provision has to be read in combination with Art. 8(a)(1) which provides the details of these publicity measures.

Member States shall ensure that information for the purposes of the identification of the out-of-commerce works or other subject-matter as well as information about the possibilities of rightholders referred to in Article $7(1)(c)$, and, as soon as it is available, information on the parties to the licence, the covered territories and the allowed uses is made publicly accessible in a single online portal from at least six months before the works or other subjectmatter are distributed, communicated to the public or made available to the public in accordance with the licence.

These provisions act as a safety mechanism for right holders. CMOs are more likely to act in their interest when right holders can vote with their feet, e.g. withdraw. The mechanism also provides a safety valve reducing the impact on right holders overall; after all, copyright provides for exclusive rights and there may be additional concerns making a right holder withdraw from the scheme. It should be noted that if a large number of right holders were to withdraw their consent, it could be interpreted as the $\mathrm{CMO}$ no longer being representative.

The most recent negotiations towards the adoption of the DSM Proposal have brought about an interesting development in relation to ECLs, outside of the issue of OOC works. Article 9(a) of the compromise text of the Proposal now puts forward a set of "measures to facilitate collecting licensing" in the form of collective licensing with an extended effect. The mechanism follows in large part the one set up for the collective licensing of OOC works under Art. 7, but is not restricted to particular types of uses or categories of users. According to paragraph 9(a)(2) the licensing mechanism would only be applicable "within well-defined areas of use where obtaining authorisations from rightholders on an individual basis is typically onerous and impractical to a degree that makes the required licensing transaction unlikely due to the nature of the use or of the types of works or other subject-matter concerned." Such a general application of the ECL system already exists in the laws of Sweden and Denmark. ${ }^{53}$ The requirement of representativeness is similar to that of the Art. 7 of the Proposal.

\footnotetext{
53 Danish Copyright Act, (Consolidated Act No. 1144 of October 23 rd, 2014), Sec. 50(2); Act on Copyright in Literary And Artistic Works (Swedish Statute Book, SFS, 1960:729, as amended up to November 1, 2013), Sec. 42h.
} 


\section{The Essential Building Blocks of a Legitimate ECL Solution}

In this section, the notion of representativeness of CMOs dealing with OOC works is analysed. We maintain that the requirement consists of three distinct but related aspects: the CMO membership, its mandate and the information of non-CMO members.

\subsection{Broad Representation}

Whether generally speaking or for the specific purposes of implementing an ECL regime, the representative character of the $\mathrm{CMO}$ is commonly assessed in relation to the "number of authors of a certain type of works which are used in [the country] within the specified field". 54 This implies that the notion of representativeness is essentially a numbers game - whoever has the most members within a certain area.

In practice, no CMO represents all authors and rights holders in its jurisdiction. There are natural gaps in its membership. First, there are industry sectors which have not developed a tradition of collective management. One major example is the film industry and therefore audiovisual works. ${ }^{55}$ Here, commercial licensing is traditionally done directly by the right holders themselves. However, significant gaps exist, even in sectors with a long history of collective management. For example, the German GEMA is based in a country of 82 million inhabitants but had less members than the Swedish STIM (with less than 10 million inhabitants). ${ }^{56}$ Secondly, not all right holders had commercial exploitation on their mind when the works were created. Collections of $\mathrm{CHIs}$ include recordings which were never intended for commercial use, such as recordings of folk music made by a CHI. Based on the lack of commercial motive, right holders in these particular works and recordings are unlikely to have them registered for management by a CMO ${ }^{57}$ There are also some who do not wish to join a CMO for other reasons. ${ }^{58}$ Thirdly, OOC works are presumed under this regime to be comparatively old. The older the objects of protection are, the larger the possibility that the rights have at some point in time been transferred to a third party, for example through inheritance upon the author's death. ${ }^{59}$ It is highly unlikely that all of these transfers would be appropriately documented. As a result, the chain of title is difficult if not impossible

\footnotetext{
54 Danish Copyright Act, (Consolidated Act No. 1144 of 23 October 2014), Sec. 50(2), which reads: "(2) Extended collective license may also be invoked by users who, within a specified field, have made an agreement on the exploitation of works with an organisation comprising a substantial number of authors of a certain type of works which are used in Denmark within the specified field. However, this does not apply, if the author has issued a prohibition against use of his work in relation to any of the contracting parties." [emphais added] This provision is similar to Sec. 38a of the Norwegian Copyright Act; Sec. 42a of the Swedish Copyright Act; and Sec. 26 of the Finnish Copyright Act. See Bulayenko (2016).

55 Janssens and Tryggvadottir (2014), p. 36.

56 Street et al. (2016).

57 Woods (2010), p. 114.

58 Zhang (2016), p. 653.

59 Zhang (2016), p. 652.
} 
to ascertain. ${ }^{60}$ In other words, it is not always clear what a CMO's repertoire actually entails in terms of the authors and specific works covered.

In addition, gaps in membership are likely to increase due to EU policy. The provisions on CMOs in the context of the CMO Directive and the DSM Proposal are quintessentially contradictory. On one hand, the CMO Directive aims to ensure competition between CMOs. Rights administration benefits from economies of scale, meaning that the administration of any particular item gets cheaper the more items there are overall. CMOs therefore have an incentive to ensure as comprehensive a membership as possible. The CMO Directive uses this economic rational to ensure that $\mathrm{CMOs}$ are responsive to their members (principal-agent problem): it allows right holders to choose the one they prefer, irrespective of location. The underlying logic is that if the right holder can vote with his feet, then CMOs will become more efficient and responsive to right holder demands by competing for members. On the other hand, the DSM Proposal presumes a system of CMO jurisdiction along national borders. For example, it refers to the CMO in the jurisdiction where the work has been first published. In other words, the DSM Directive presumes that CMOs do not compete and will not, given that no alternative mechanism is available. Therefore, if the CMO Directive is a success, then there will be more than one relevant CMO in the field for each type of right and work - as is presumed by the MoU. In other words, the tools contradict each other: they cannot both be successful.

Following the gaps in the membership, it cannot even be presumed that the largest CMO represents the most right holders for any particular use. It should be noted that fixed numerical indicators such as "majority" are difficult ${ }^{61}$ : even if there is only one CMO in a field, it does not automatically imply that it represents a majority of right holders in a particular field. ${ }^{62}$ The degree of representativeness is going to vary by sector and country. Similarly, existing schemes assess the representativeness in terms of membership always in combination with the second criterion: mandate. For example, the Danish Ministry of Culture assesses the representativeness of the $\mathrm{CMO}$ as a combination of membership size and the specific use (exclusive right) in question. ${ }^{63}$ In other words, while the absolute size of the membership matters, it can only be understood in respect to the specific right in question. This means the most representative CMO may differ according to the type of use. If the CMO Directive is successful in creating inter-CMO competition, this aspect will gain in importance. In addition, it should be noted at this point that most jurisdictions only allow for one CMO to actually license the content in the ECL context. ${ }^{64}$ This principle should be strengthened as Zhang points out; having more than one CMO can be confusing for non-members. ${ }^{65}$

\footnotetext{
60 This issue has been discussed extensively in respect to the orphan works, see for example Woods (2010); Ranaivoson et al. (2013), p. 674; or Schroff (2015), pp. 71-78.

61 Riis and Schovsbo (2012), p. 937.

62 Zhang (2016), pp. 667-668; Riis and Schovsbo (2012), p. 937.

63 Hugenholtz et al. (2014), pp. 25-26.

64 The one exception is Finland. See also Zhang (2016), p. 648.

65 Zhang (2016), p. 648.
} 


\subsection{Proper Mandate}

The part of the representativeness criterion relating to the user's "right to exploit works of the same nature" 66 directly concerns the CMOs mandate and its capacity to grant licences with respect to the rights it administers.

To be entitled to grant licences in the first place, whether on behalf of nonmembers or not, the CMO must be entrusted by its members with an explicit mandate to represent specific rights. Following the CMO Directive, these rights have to be explicitly listed. ${ }^{67}$ In the context of the digitisation and dissemination of presumably old(er) cultural heritage material, the question whether the CMO has obtained from the rights owners, their heirs or assignees, the necessary mandate to administer the digital rights in these older works is very relevant. New uses such as online use can also not be automatically presumed to have been transferred, with the rules varying significantly between member states. ${ }^{68}$ A CMO managing the rights in a particular work can therefore not necessarily license online use if its mandate is based on older contracts, in particular from the pre-digital age. In practice, the CMO has to actively update the contracts. This can be a major administrative burden ${ }^{69}$ not many CMOs will have fully complied with. ${ }^{70}$ Therefore, older contracts and rights fragmentation mean that even if the rights in a particular copyright work are managed by a CMO, the mandate does not necessarily cover all economic rights.

Current practice shows how this requirement can be implemented, and equally important how it cannot. The Danish Ministry of Culture assesses the representativeness of the CMO in its decision, interpreting this as a combination of membership size and the specific use (exclusive right) in question. ${ }^{71}$ In other words, the Ministry of Culture considers the mandate the CMO has from its members both in respect of the type of work and the exclusive right in questions. In this context, the CMO's statutes and therefore membership contracts form part of this examination. ${ }^{72}$ Similarly, in the case of OOC works published in Germany before 1 January $1966^{73}$ in books, journals, newspapers, magazines or in other writings, the

\footnotetext{
66 Danish Copyright Act, Sec. 50(3): "The extended collective license gives the user right to exploit other works of the same nature even though the authors of those works are not represented by the organisation". This provision is similar to Norwegian Copyright Act, Sec. 26; Finnish Copyright Act, Sec. 26(1); Swedish Copyright Act, Sec. 42a: "The extended collective license confers to the user the right to exploit works of the kind referred to in the agreement $[\ldots]$ “.

67 See CMO Directive, Art. 5(1) and (7).

68 Dusollier et al. (2014), p. 35.

69 This is explicitly recognised in the proposed Directive under recital 19 which states: "A requirement for the consent of rightholders in the authorisation to the management of each right, category of rights or type of works and other subject-matter should not prevent the rightholders from accepting proposed subsequent amendments to that authorisation by tacit agreement in accordance with the conditions set out in national law."

70 On the discussion about CMOs and knowledge of their own repertoire and rights, see Schroff (2015).

71 For a detailed discussion, see Hugenholtz et al. (2014), pp. 25-26.

72 Hugenholtz et al. (2014), p. 26.

73 Using a cut-off date like this has the practical side effect that works before this date are presumed outof commerce, negating the need for a search and therefore reducing the overall costs. Janssens and Tryggvadottir (2014), p. 33.
} 
OOC provision in the German Collective Management Organisations Act explicitly states that only those CMOs which already manage the specific right in question are presumed to manage the rights of non-members. ${ }^{74}$ For more recent works, Sec. 1371 of the German Copyright Act establishes another presumption of grant of rights on older works with respect to new types of uses:

(1) Where between 1 January 1966 and 1 January 2008, the author has granted another person all essential rights of use, exclusively as well as without limitation of place and time, the rights of use which were not known at the time the contract was concluded shall be deemed also to have been granted to the other person, so far as the author does not indicate to the other person that he objects to such use. In respect of types of use that were already known on 1 January 2008 the objection may be made only within one year. Otherwise the right of objection shall expire after three months have elapsed since the other person sent the author, at the address last known to the sender, the information concerning the intended commencement of the new type of use of the author's work. The first to third sentences shall not apply to rights of use which have become known in the meantime and which the author has already granted to a third person. ${ }^{75}$

On the basis of these provisions, the contract signed between the VG Wort (the German CMO for writings) and its authors and publishers provides for the explicit grant of all rights necessary to allow the proper licensing of OOC works of their members, including the rights arising from Secs. 16, 19a and 1371 of the Copyright Act or Sec. 51 of the Collective Management Organisations Act. ${ }^{76}$

By contrast, the former French OOC system, created pursuant to the Act No. 2012-287 of March 1, 2012, on the Digital Exploitation of Unavailable Books of the 20th Century and the implementing decree No 2013-182, ${ }^{77}$ gave a prime example of a CMO operating on the basis of an insufficient mandate. The Act essentially established a system made up of two components. First, the law created a free and publicly accessible database of OOC books, known as the Registre des Livres Indisponibles en Réédition Électronique (ReLIRE), to be administered by the Bibliothèque nationale de France (BNF). The second component concerned the licensing of these OOC books. When a book had been entered in the database for

\footnotetext{
${ }^{74}$ Collective Management Organisations Act, Sec. 51: "it shall be presumed that a collecting society which manages the rights of reproduction $(\$ 16$, Copyright Act) and of making works available to the public ( $\$ 19$ a, Copyright Act) in out-of-commerce works and which is authorised to do so ( $\$ 77)$ is authorised, within its scope of activity, to also grant users these rights in works of those rightholders who have not mandated the collecting society with the management of their rights". Translation available at https://www.gesetze-im-internet.de/englisch_vgg/englisch_vgg.html.

75 Translation available at http://www.gesetze-im-internet.de/englisch_urhg/englisch_urhg.html.

${ }^{76}$ See Verwertungsgesellschaft Wort, "Wahrnehmungsvertrag”, available at: http://www.vgwort.de/ fileadmin/pdf/wahrnehmungsvertrag/Muster_Wahrnehmungsvertrag_Autor_10.9.16.pdf. For a detailed legal analysis, please see, Ahlberg and Götting (2018), VGG § 51, especially for the overlap between the old 13th WahrnG and the new law.

77 Decree No 2013-182 of 27 February 2013, implementing Arts. L. 134-1 to L. 134-9 of the French Intellectual Property Code and relating to the digital exploitation of out-of-print 20th century books) (JORF No 51 of 1 March 2013, p. 3835).
} 
more than six months and had not been subject to an opt-out by the right holder or author, the Act stated that the right to authorise its (commercial) reproduction and representation in digital form was to be exercised by a collecting society recognised by the Minister of Culture, the SOFIA. In May 2013, two French authors of literary works, Mr Soulier and Ms Doke, filed a request with the Conseil d'État (Council of State, France). The Conseil d'État stayed the proceedings and referred the case to the CJEU, asking the Court to issue a preliminary ruling on the following question:

Do Articles 2 and 5 Information Society Directive preclude legislation, such as that established in Articles L. 134-1 to L. 134-9 CPI, that gives approved collecting societies the right to authorise the reproduction and the representation in digital form of "out-of-print books", while allowing the authors of those books, or their successors in title, to oppose or put an end to that practice, on the conditions that it lays down $?^{78}$

The CJEU confirmed that the French law was too broad to fit into any of the exceptions provided for in the Information Society Directive. ${ }^{79}$ As a result, the law must comply with the economic rights. Since the economic rights are exclusive rights, their exercise required the consent of the right holder. The Court held that the provisions of the Information Society Directive should not be interpreted as requiring explicit consent ${ }^{80}$; there are situations - for example, in relation to the interpretation of the concept of "new public" - in which the author can be presumed to have agreed implicitly. ${ }^{81}$ However, valid implied consent is subject to necessary pre-conditions, namely that every author is actually informed of the future use of his work by a third party, and that he has the means at his disposal to prohibit it if he so wishes. ${ }^{82}$ The court, however, did not actually address the question of mandate as such and instead chose to focus on implied consent.

It is our contention that the Court of Justice should have gone further in its reasoning and not limit itself to the examination of the registration of books in the ReLIRE database. To include a book in a publicly accessible list held by the BNF cannot be regarded as authorising the SOFIA to grant commercial exploitation licenses to third parties. It follows from the recently implemented Collective Management Directive, ${ }^{83}$ that the mandate of a CMO cannot be presumed. It must be laid down specifically either in the law or in the exploitation contract binding the rights owner to the CMO. In the case of the SOFIA and the management of rights of reproduction and making available to the public of OOC works, Art. L. 134-3-I CPI

\footnotetext{
78 Soulier and Doke, para. 24.

79 Soulier and Doke.

80 Soulier and Doke, para. 35.

${ }^{81}$ See especially Nils Svensson and Others v. Retriever Sverige AB, Case C-466/12, Judgment of 13 February 2014 - Svensson, paras. 25-28, 31.

82 Soulier and Doke, paras. 35-39.

${ }^{83}$ CMO Directive as implemented in France by Ordonnance ${ }^{\circ}$ 2016-1823 du 22 décembre 2016 portant transposition de la directive 2014/26/UE du Parlement européen et du Conseil du 26 février 2014 concernant la gestion collective du droit d'auteur et des droits voisins et l'octroi de licences multiterritoriales de droits sur des œuvres musicales en vue de leur utilisation en ligne dans le marché intérieur, Art. L. 322-3 CPI.
} 
states that "where a book has been entered in the database referred to in Article L. 134-2 for more than six months, the right to authorise its reproduction and representation in digital form is exercised by [a $\mathrm{CMO}$, approved for that purpose by the Minister of Culture."

The above provision merely states that the rights are "exercised by" the relevant CMO, e.g. SOFIA. Article L. 134-3-I CPI creates no express presumption and operates no explicit statutory transfer of rights in favour of the SOFIA. Simply stating that the SOFIA exercises the right to authorise an OOC work's reproduction and representation in digital form does not convey any valid right on the SOFIA. This is in sharp contrast with Art. L. 122-10 CPI, for example, which creates an explicit transfer of the author's right of reprographic reproduction in favour of the Centre Français de la Copie (CFC). ${ }^{84}$ At most, Art. L. 134-3-I CPI suggests a presumption of mandate in favour of SOFIA, not an express transfer of rights.

As the text of the law is insufficient to give the SOFIA a clear mandate, the CMO needs to acquire the express permission from the rights owners to exercise the rights on their behalf. Until 2018, the deed of adhesion that authors signed upon joining SOFIA made no reference to the rights relating to unavailable books. The deed of adhesion was modified after the Conseil d'État concluded with respect to the illegal character of Arts. L. 134-1 to 9 CPI, thereby reaffirming the finding of the CJEU in the Soulier and Doke case. ${ }^{85}$ By adhering to the SOFIA, authors now agree

[f]or all countries and for the duration of the Society, to bring under its management ("apporte en gérance") the following rights with respect to all [his/her] existing and future works that are covered by a publishing contract: remuneration for public lending, - Remuneration for digital private copying, right of rental, - remuneration for the exploitation of unavailable books in digital form, - sums coming from the CFC. ${ }^{86}$

French copyright law distinguishes between two forms of transfers: "apport simple" and "apport en gérance". The first brings the rights from the right holder to the CMO in full ownership, while the second only confers a right to exercise the right. ${ }^{87}$ To be able to authorise or prohibit acts of reproduction and making available to the public of OOC works, i.e. to be able to grant licences to third parties, the deed of adhesion to the SOFIA would have required an "apport simple" of both of these rights, but neither is mentioned in the list. Instead, the role of the SOFIA generally consists in negotiating, collecting and distributing the sums of money collected by

\footnotetext{
${ }^{84}$ Intellectual Property Code, Art. L. 122-5-10 first sentence reads as follows: "The publication of a work shall imply assignment of the right of reprographic reproduction to a society governed by Title II of Book III and approved to such end by the Minister responsible for culture."

85 Conseil d'Etat, Decision of 7 June 2017, N 368208, ECLI:FR:CECHR:2017:368208.20170607.

${ }^{86}$ CFC collects the reprography fees. SOFIA Adhesion deed states: "Je fais apport en gérance, pour tous pays et pour la durée de la Société, sur toutes mes auvres créées et futures faisant l'objet d'un contrat d'édition, des droits suivants : rémunération au titre du prêt en bibliothèque, - rémunération pour copie privée numérique, - droit de location, - réumunération au titre de l'exploitation des livres indisponibles en réédition électronique,- sommes en provenance du Centre Français d'exploitation du droit de Copie". See http://www.la-sofia.org/sofia/webdav/site/Sofia/shared/Adh\%C3\%A9sion\%20auteur/Acte\%20adh\% C3\%A9sion\%20Auteur\%20Sofia.pdf.

87 Nérisson (2013), p. 155.
} 
the relevant CMOs, on the basis of remuneration rights paid in respect of works covered by a publishing contract. Moreover, no implied or indirect licence in favour of SOFIA should be read into any publishing contract signed between authors and "publishers having the right to reproduce the work in printed form". SOFIA's daily business is not that of granting licenses for the exploitation of works on the basis of exclusive rights. In the absence of an unequivocal permission obtained directly from the rights owners, the SOFIA therefore did not have a legitimate mandate to grant licences pursuant to Art. L. 134-6 CPI.

Coming back to the Soulier and Doke case, the obligation placed by the CJEU on the SOFIA to actually and individually inform rights owners about the ReLIRE system cannot remedy the absence of a proper mandate. Such a mandate is paramount, not only for the good functioning of the relationship between a CMO and its members but also for the establishment of any valid system of ECL. Furthermore, ECL schemes are based on the representativeness of the CMO to justify the inclusion of non-members in the licenses that are issued. ${ }^{88}$ The representativeness of a CMO can only be assessed in relation to the CMO's membership, where the membership exists either by virtue of the law (for example, through a valid presumption of transfer) or of a contractual arrangement. The fact that the CJEU in the Soulier and Doke decision makes no reference to the SOFIA's mandate or to its relationship with members or with potential non-members could be construed as an additional indication that the French system was alien to any kind of extended collective licensing system. In any case, Art. L. 134-4 CPI lists among the requirements with which a CMO must comply the obligation to be recognised by the Ministry of Culture, but nowhere does it refer to the obligation of the CMO to be representative of the rights holders whose rights it administers.

\subsection{Obligation to Inform and the Notion of Tacit Approval}

Finally, even if a CMO represents a broad number of rights owners and has a proper mandate, any OOC scheme needs to provide for an efficient mechanism to allow authors and right holders to end the OOC status of a work. ${ }^{89}$ In this respect, no formalities should apply. ${ }^{90}$ In other words, opt-outs need to be facilitated as much as possible, thus lowering the threshold. This means in practice that the mechanism has to: (1) reach the largest number of CMO non-members; (2) clearly explain, through the information provided, the purpose and scope of the agreement; and (3) be as easy and inexpensive for the non-member as possible. ${ }^{91}$

While the decision in Soulier and Doke does not apply to ECLs, its discussion of tacit approval needs to be considered. In particular, while the Court of Justice in

\footnotetext{
88 This is discussed in more detail below.

${ }^{89}$ This principle is well established, see for example the MoU, principle 2.5 or the Orphan Works Directive, Art. 5.

90 Opinion of AG Wathelet, para. 40; Soulier and Doke, paras. 50-51. It should be noted that the Berne Convention in principle prohibits formalities but it is does not prohibit an opt-out scheme as such. Zhang (2016), p. 665.

91 Ginsburg (2017), p. 6.
} 
Soulier and Doke invalidated the French system based on implied consent, as it infringed upon the exclusive rights granted under the Information Society Directive, the question of tacit approval by authors remains, not least because it was not excluded per se. ${ }^{92}$ As a result, it is in principle possible that a narrower licensing scheme can be based on tacit approval, subject to information requirements, provided the $\mathrm{CMO}$ has a solid mandate from its members in the first place. The following discussion will outline the principles that should be complied with in the context of OOC schemes to ensure that the requirements of tacit approval by the right holder(s) are met.

Under Art. 7(3)(c) DSM Proposal, the ECL effect is conditional on an opt-out possibility by the right holder. It is clear from case law that this burden cannot be too onerous for the right holder. The Court held in Soulier and Doke that the author of a work must be able to put an end to the exercise, by a third party, of rights of exploitation in digital format without having to submit beforehand to a formality which consists in proving that he is the sole owner of the right in the work. ${ }^{93}$ Here the specific opt-outs built into the French system were problematic and demonstrated a system which was too burdensome in practice. ${ }^{94}$

There were several ways in which a book could be withdrawn from the French ReLIRE database and therefore be removed from the OOC scheme. In general, the author of an unavailable book or the publisher having the right of reproduction in a printed form of this book could oppose in written form the exercise of the right of authorisation by the SOFIA no later than six months after the entry of the book in the ReLIRE database. After this date, the hurdles for opting-out were higher. The author and the publisher having the right to reproduce an unavailable book in printed form could at any time jointly notify the SOFIA of their decision to withdraw from the scheme. The publisher who objected to the inclusion of his book in the ReLIRE database must proceed with the digital exploitation of that book within two years of the notification of his opposition. If the publisher failed to exploit the work, the rights reverted back to the SOFIA. In other words, even if the publisher was the sole right holder, he had to meet additional requirements to exercise his exclusive right - to acquire consent from the author and actively exploit the work digitally.

In addition to these general rules, two additional opt-outs were available for authors. First, after the expiration of the first six months, the author of an unavailable book could oppose the exercise of the right of reproduction or representation of that book if he considered that the reproduction or representation of the book was likely to harm his honour or reputation. ${ }^{95}$ This was essentially an implementation of the moral right of authors to withdraw works but in line with it, the threshold of proof was rather high. Secondly, the author of an unavailable book could at any time decide to withdraw individually from the scheme, but only provided he proved sole ownership of the right to authorise the reproduction and

\footnotetext{
92 Soulier and Doke para. 35.

93 Soulier and Doke, paras. 46-51.

94 Bulayenko (2016).

95 Intellectual Property Code, Art. L. 134-4 I third indent.
} 
representation of the book in digital form. ${ }^{96}$ However, trying to establish in evidence that certain exclusive rights in OOC works have not been transferred to a third party is virtually impossible in practice. Overall, the burden of actions which needed to be taken to opt-out after the first six months in particular were considered onerous by the Court, constituting a non-permissible formality under the Berne Convention. ${ }^{97}$ In this sense, the Soulier and Doke case essentially shows how it cannot be done.

It also follows from Soulier and Doke that the efforts to inform authors who are not CMO members are crucial. Indeed, the CMO Directive already imposes clear transparency measures on CMOs: they have to publish information on their internal organisation, their revenue collection, their agreements (at least the standard ones) and dispute mechanisms. Most importantly here though, CMOs are required to actively trace right holders which are not members but for whose works revenues were collected. ${ }^{98}$ It further states that this search has to be carried out first via contacting other CMOs and at a later stage the public at large if earlier attempts to identify the right holder were not successful. In other words, CMOs are already under an obligation to actively trace non-members. Under Art. 9 DSM Proposal, the role of publicity measures as part of the stakeholder dialogue is highlighted. The difference to the CMO Directive is the focus: while the CMO Directive focuses on the individual, the DSM Proposal centers on the organisational level. It therefore follows that under EU law, tacit approval requires transparency and efforts to trace right holders as far as is reasonable. Tacit approval here has to be interpreted as ensuring that as many authors and right holders as possible are informed of the OOC scheme in general and the use of their work in particular.

It should be noted here that this problem of large numbers of unknown right holders is not new and a precedent has been set in the Orphan Works Directive (Directive 2012/28/EU, hereinafter OWD). The OWD sought a way to deal with works the authors and rights holders of which are unknown or untraceable, thereby preventing CHIs from obtaining permission to use these works. To ensure all possible avenues are covered, the OWD's Annex lists the kinds of sources which can hold right holder and authorship information, based on the principle that a relevant right holder or author can be identified and contacted if the listed institutions are consulted. With the exception of general registers to identify a work as such, all sources on individuals either refer to CMOs or associations of particular stakeholder groups. ${ }^{99}$ In this respect, CMOs and stakeholder associations are presumed to have sufficient links with the relevant creative community to identify and reach relevant right holders and authors. If they all fail, then the right holder/ author is presumed to be unidentifiable.

In other words, it is already established in EU law that CMOs in combination with interest associations provide the largest possible coverage of the relevant creative community. This reasoning in turn also means that the established networks

\footnotetext{
96 Intellectual Property Code, Art. L. 134-6, second sentence.

97 Soulier and Doke, paras. 49-51.

98 CMO Directive, Art. 13(3).

99 Orphan Works Directive, Annex; Schroff et al. (2016), p. 286.
} 
maintained by CMOs and stakeholder associations provide the most extensive information network. After all, each of these organisations has their own network and channels of communication with their members as well as the relevant creative community more broadly. This includes, for example, providing for forums for discussion, an online presence as well as active participation at key industry events or major conventions. In addition, CMOs should publish information on the agreements, works and right holders not identified as well as the mechanisms to claim royalties on their websites. ${ }^{100}$ As a result, relying on these established networks, the details of a licensing scheme can be communicated as widely as possible within the relevant community. In combination with the narrow scope of the schemes, this will most likely satisfy the notification and tacit approval requirements of non-members.

\section{Conclusion}

As the previous discussion has shown, existing EU law, case and soft law as well as the DSM Proposal, provide significant guidance on what minimum criteria a CMO needs to meet in the context of extended collective licensing. In particular, only a proper mandate and treatment of non-members can make any ECL legitimate. The following key principles can be ascertained. First, without an underlying legal provision, CMOs licensing works of non-members are consciously overstepping their boundaries as they license something to which they have no claim. This means that ECL schemes need to have a basis in the law at all times. Secondly, CMOs need to manage the kind of right in the type of work in question: only if they already have an explicit mandate from their members to manage these rights in works, can a CMO issue licenses. This has to be the fundamental pillar of all licensing schemes involving OOC works as it influences all other aspects. Thirdly, the CMO has to be representative of the right holders affected by an OOC scheme. As demonstrated in this article, while most commentators see this as a question of absolute membership size, this can be misleading. There are gaps in the membership and their size and relevance will vary according to the type of right, the type of work and proposed use in question. As a result, it is the combination of membership size with the type of work, exclusive right and nature of the work ((e.g. non-commercial works (as discussed above), age, etc.)) which needs to be taken into account.

ECL schemes can only be sufficiently legitimate to presume tacit approval by non-members if this assessment of the three criteria is carried out carefully. Finally, any ECL scheme needs to actively seek to inform authors and right holders. While this is already an obligation under the CMO Directive, informing non-members is crucial for the notion of tacit approval and therefore the coverage of non-members. The new aspect here is that in addition to tracing individual right holders, largescale publication efforts are required under the DSM Proposal. It has been argued here that this can best be achieved by cooperating with the key organisations identified by the OWD, a Directive which addresses a similar issue. By including a

100 Zhang (2016), p. 668. 
range of stakeholder organisations - all of which have links and communication channels to their respective communities - authors are more likely to be aware of an ECL system, strengthening the case for tacit approval.

Open Access This article is distributed under the terms of the Creative Commons Attribution 4.0 International License (http://creativecommons.org/licenses/by/4.0/), which permits unrestricted use, distribution, and reproduction in any medium, provided you give appropriate credit to the original author(s) and the source, provide a link to the Creative Commons license, and indicate if changes were made.

\section{References}

Ahlberg H, Götting H-P (eds) (2018) BeckOK Urheberrecht, 20th edn. C.H. Beck, Munich

Axhamn J, Guibault L (2011) Solving Europeana's mass-digitization issues through extended collective licensing? Nord Intellect Prop Law Rev 6:509-516

Bensamoun A (2014) The French out-of-commerce books law in the light of the European Orphan Works Directive. Queen Mary J Intellect Prop 4(3):213-225

Beunen A, Guibault L (2011) Brussels Memorandum of Understanding inzake digitalisering en online beschikbaarstelling van out-of-commerce boeken en tijdschriften. AMI 6:221-229

Bulayenko O (2016) Permissibility of non-voluntary collective management of copyright under EU Law - the case of the French law on out-of-commerce books. JIPITEC 7(1):51-68

Busse T (2018) Crossing the digital rubicon: Google Books and the dawn of an electronic literature revolution. Houst Bus Tax Law J 18:119-149

Drexl J, Nérisson S, Trumpke F (2013) Comments of the Max Planck Institute for Intellectual Property and Competition Law on the proposal for a Directive of the European Parliament and of the Council on Collective Management of Copyright and Related Rights and multi-territorial licensing of rights in musical works for online uses in the internal market COM (2012)372. Int Rev Intellect Prop Compet Law 44(3):263-292

Dusollier S, Ker C, Iglesias M, Smits Y (2014) Contractual arrangements applicable to creators: law and practice of selected member states. Study for the European Parliament. http://www.europarl.europa. eu/RegData/etudes/etudes/join/2014/493041/IPOL-JURI_ET\%282014\%29493041_EN.pdf. Accessed 6 June 2018

Ginsburg J (2017) Extended collective licenses in international treaty perspective: issues and statutory implementation. Columbia Public Law Research Paper No. 14-564. https://papers.ssrn.com/sol3/ papers.cfm?abstract_id=3068997. Accessed 6 June 2018

Gomez P, Keller P (2015) The missing decades: the 20th century black hole in Europeana. http://pro. europeana.eu/blogpost/the-missing-decades-the-20th-century-black-hole-in-europeana. Accessed 6 July 2017

Guibault L (2014) Collective rights management directive. In: Stamatoudi I, Torremans P (eds) Copyright law in the European Union. Edward Elgar, Cheltenham, pp 696-796

Guibault L (2015) Cultural heritage online? Settle it in the country of origin of the work. JIPITEC 6(3):173-191

Haunss S (2013) The changing role of collecting societies in the Internet. Internet Policy Rev 3(3):1-8

Hugenholtz B, Van Gompel S, Guibault L, Obradovic R (2014) Extended collective licensing: panacee voor massadigitalisering? Institute for Information Law, Amsterdam. https://www.ivir.nl/ publicaties/download/1471.pdf. Accessed 6 July 2017

Janssens M-C, Tryggvadottir R (2014) Facilitating access to orphan and out of commerce works to make Europe's cultural resources available to the broader public. https://papers.ssrn.com/sol3/papers. cfm?abstract_id $=2538097$. Accessed 6 June 2018

Janssens M-C, Tryggvadottir R (2016) Orphan works, out-of-commerce works and making the European cultural heritage available: 'are we nearly there yet'? In: Stamatoudi I (ed) New developments in EU and international copyright law. Kluwer Law International, Alphen aan den Rijn, pp 189-209

Kretschmer M (2005) Access and reward in the information society: regulating the collective management of copyright. http://eprints.gla.ac.uk/71496/. Accessed 6 July 2017 
Metzger A, Heinemann T (2015) The Right of the author to grant licenses for non-commercial use: creative commons licenses and the directive on collective management. JIPITEC 6(1):11-22

Nérisson S (2013) La gestion collective des droits des auteurs en France et en Allemagne: quelle légitimité?. Institut de Recherche Juridique de la Sorbonne, Paris

Ranaivoson H, Iglesias M, Vondracek A (2013) The costs of licensing for online music services: an exploratory analysis for European states. Mich State Int Law Rev 21(3):666-686

Riis T, Schovsbo J (2012) Extended collective licenses in action. Int Rev Intellect Prop Compet Law 43(8):930-950

Schroff S (2015) Europeana sounds and copyrights: the need for and challenges in licensing archival materials. Institute for Information Law, Amsterdam. http://pro.europeana.eu/files/Europeana Professional/Projects/Project_list/Europeana_Sounds/Other\%20documents\%20related\%20to\% 20the\%20project/Europeana\%20Report\%20by\%20IVIR\%20final.pdf. Accessed 6 July 2017

Schroff S, Street J (2017) The politics of the digital single market: culture vs. competition vs. copyright. Inf Commun Soc. https://doi.org/10.1080/1369118x.2017.1309445

Schroff S, Favale M, Bertoni A (2016) The impossible quest: problems with diligent search for orphan works. Int Rev Intellect Prop Compet Law 48(3):286-304

Street J, Laing D, Schroff S (2016) Regulating for creativity and cultural diversity: the case of collective management organisations and the music industry. Int J Cult Policy 40(3):227-259

Strowel A (2011) The European extended collective licensing model. Columbia J Law Arts 34:665-669

Woods T (2010) Multi-territorial licensing and the evolving role of collective management organisation. In: Gervais D (ed) Collective management of copyright and related rights, 2nd edn. Kluwer Law International, Alpen aan de Rijn, pp 105-134

Zhang Z (2016) Transplantation of an extended collective licensing system - lessons from Denmark. Int Rev Intellect Prop Compet Law 47(6):640-672 